LBNL-48647, revised IEEE TPS Version

Accepted for publication in

IEEE Transactions on Plasma Science, vol. 29, no.5 (2001)

presented as Invited Talk 6-I01

at the 19th International Symposium on Discharges and Electrical Insulation in Vacuum

(ISDEIV 2000)

September18-22, 2000

Xi'an, China

\title{
Ultrathin Diamond-like Carbon Films Deposited by Filtered Carbon Vacuum Arcs
}

\author{
André Anders ${ }^{1}$, Fellow IEEE, Walton Fong ${ }^{2}$, Ashok Kulkarni ${ }^{3}$, Francis W. Ryan ${ }^{3}$, and \\ C. Singh Bhatia ${ }^{4}$ \\ ${ }^{1}$ Lawrence Berkeley National Laboratory, University of California, Berkeley, California 94720 \\ ${ }^{2}$ University of California, Department of Mechanical Engineering, Berkeley, California 94720 \\ ${ }^{3}$ Read-Rite Corporation, 44100 Osgood Road, Fremont, California 94539 \\ ${ }^{4}$ IBM, Advanced Magnetic Recording Laboratory, 5600 Cottle Road, San Jose, California 95193
}

Abstract December1999

Symposium Paper May 2000

final, revised version for IEEE Transactions on Plasma Science: July 13, 2001

This work was supported through the CRADA BG98-084(01) of the ER-LTR Program of the U.S. Department of Energy, under Contract No. DE-AC03-76SF00098, by CVC-Veeco, Inc., the CRADA Industrial Partner, by the National

Storage Industry Consortium (NSIC), and the Computer Mechanics Laboratory at the University of California at Berkeley. 


\title{
Ultrathin Diamond-like Carbon Films Deposited By Filtered Carbon Vacuum Arcs
}

\author{
André Anders ${ }^{1}$, Fellow IEEE, Walton Fong ${ }^{2}$, Ashok Kulkarni ${ }^{3}$, Francis W. Ryan ${ }^{3}$, and \\ C. Singh Bhatia ${ }^{4}$ \\ ${ }^{1}$ Lawrence Berkeley National Laboratory, 1 Cyclotron Road, MS 53, Berkeley, California 94720 \\ ${ }^{2}$ University of California, Department of Mechanical Engineering, Berkeley, California 94720 \\ ${ }^{3}$ Read-Rite Corporation, 44100 Osgood Road, Fremont, California 94539 \\ ${ }^{4}$ IBM, Advanced Magnetic Recording Laboratory, 5600 Cottle Road, San Jose, California 95193
}

\begin{abstract}
Ultrathin $(<5 \mathrm{~nm})$ hard carbon films are of great interest to the magnetic storage industry as the areal density approaches $100 \mathrm{Gbit} / \mathrm{in}^{2}$. These films are used as overcoats to protect the magnetic layers on disk media and the active elements of the read-write slider. Tetrahedral amorphous carbon films can be produced by filtered cathodic arc deposition, but the films will only be accepted by the storage industry only if the "macroparticle" issue has been solved. Better plasma filters have been developed over recent years. Emphasis is put on the promising twist filter system - a compact, open structure that operates with pulsed arcs and high magnetic field. Based on corrosion tests it is shown that the macroparticle reduction by the twist filter is satisfactory for this demanding application, while plasma throughput is very high. Ultrathin hard carbon films have been synthesized using Sfilter and twist filter systems. Film properties such as hardness, elastic modulus, wear, and corrosion resistance have been tested.
\end{abstract}

Index Terms: diamond-like carbon, cathodic vacuum arc, macroparticle filtering, magnetic storage, carbon overcoats 


\section{INTRODUCTION}

Ultrathin $(<5 \mathrm{~nm})$ hard carbon films are used as protective overcoats on hard disks and readwrite heads. The tribological properties of the head-disk interface are not only of mechanical but also of chemical nature: the overcoat should protect the magnetic layers against wear and corrosion $[1,2]$. The areal density of information stored in disk drive products increased at an amazing rate of over $65 \%$ for many years rate, and continues to accelerate to even greater rates [3]. To accomplish this, the "magnetic spacing" between the magnetic layers of the disk and read/write sensor of the head must continue to decrease. The magnetic spacing includes the overcoats, lubrication, and the fly height. Thinner overcoats allow the read-write head to be closer to the magnetic layer of the disk, and hence, the size of individual bits on the disk to be smaller. As we work toward an areal density of 100 Gbit/in ${ }^{2}$, the magnetic spacing approaches the sub-10-nm regime (pseudo-contact recording) and overcoat thickness must shrink to 1-2 nm. Overcoats currently used are sputtered or ion-beam deposited diamond-like carbon films, typically doped with hydrogen or nitrogen. They cease to provide acceptable levels of corrosion protection when the film thickness is less than $5 \mathrm{~nm}$.

Overcoats need to be tough (hard and elastic), chemically inert, pinhole-free, and compatible with the lubricant. The challenge of ultrathin film synthesis is to make the films as thin as possible and still continuous, as opposed to an assembly of islands.

Nucleation and growth of ultrathin films is a field of intense research. For carbon, it is well known that films that are rich in $\mathrm{sp}^{3}$ (diamond) bonds should be grown in a kinetic mode at low temperature (less than $200^{\circ} \mathrm{C}$, preferably room temperature), with film-forming carbon atoms or ions having an energy of about $100 \mathrm{eV}$. This energy is optimized for subplantation film growth of diamond-like carbon [4-10]. If the energy is too low, say less than $20 \mathrm{eV}$, ions do not have the kinetic energy to penetrate the surface; if the energy is too high, thermal spikes and a general enhancement of the temperature will allow the carbon atoms of the film to move to configurations of smaller energy. In both cases, the films tend to be more graphitic with characteristic $\mathrm{sp}^{2}$ bonds.

Diamond-like films are characterized by an outstanding combination of advantageous properties: they can be very hard, tough, super-smooth, chemically inert, well adherent to the substrate, and compatible with lubricants. They can be deposited fast, efficiently, at low cost, and on room temperature substrates. The various deposition methods result in a variety of diamond-like films. Widely used are hydrogenated diamond-like carbon (DLC or a-C:H) [11], nitrogen-doped amorphous carbon (a-C:N) [12] or amorphous carbon nitride $\left(\mathrm{CN}_{\mathrm{x}}\right)$ [13-15], hydrogenated carbon nitride $\left(\mathrm{CH}_{\mathrm{x}} \mathrm{N}_{\mathrm{y}}\right)$, hydrogen-free amorphous carbon (a-C) [16], silicon-doped amorphous carbon (a$\mathrm{C}: \mathrm{Si}$ ) or silicon carbide (SiC) [17], and metal-doped amorphous carbon (a-C:Me) [18]. Amorphous carbon films (a-C) that have more than $80 \%$ tetrahedral $\left(\mathrm{sp}^{3}\right)$ bonding are referred to as tetrahedral amorphous carbon (ta-C) [7, 9, 19], or sometimes even as "amorphous diamond." [20, 21]

There are large variations even within each class of materials, depending on the method and parameters of deposition. Diamond-like carbon films can be synthesized by argon sputter deposition using a graphite target [12, 22], by pulsed laser ablation of graphite [19], direct ion beam deposition [23], plasma beam deposition [24], mass-selected ion beam deposition [25, 26], electron-cyclotronresonance plasma chemical vapor deposition (ECR plasma CVD) [27], radio-frequency-CVD [11], and by filtered cathodic arc plasma deposition [6, 16, 20,21]. Research over the last years has identified filtered cathodic arc deposition as one of the promising techniques for hard carbon films thinner than $5 \mathrm{~nm}[28,29]$. The greatest challenge is the complete removal of "macroparticles" that are generated at the cathode spot.

This paper focuses on the deposition of ultrathin amorphous carbon films using filtered vacuum-arc carbon plasma. We discuss first the generation of plasma and macroparticles as well as methods of macroparticle removal by curved filters. Particular attention is given to the "twist filter" 
system which is the latest advancement in this field. In the last section, we report about tests of the carbon films made by S-filtered and twist-filtered cathodic arc systems.

\section{MACROPARTICLE-FREE CARBON PLASMA}

\section{A. Cathodic arc carbon plasma}

Cathodic arc plasmas are characterized by a very high degree of ionization, with multiply charged ions present [30]. Carbon plasma is dominated by ions of charge state 1+. The carbon plasma flows with a high velocity of about $2 \times 10^{4} \mathrm{~m} / \mathrm{s}$, and even somewhat greater carbon ion velocities have been measured recently [31]. Both the high degree of ionization and plasma velocity result from explosive processes at cathode spots [32]. The "vacuum" arc is a non-stationary high-pressure phenomenon driven by a very high power density of at least $10^{13} \mathrm{~W} / \mathrm{m}^{2}$.

Solid cathode material is transformed to dense plasma that expands while moving away from the spot area. Not only plasma is produced but also debris particles that are liquid in case of metal cathodes and liquid or solid in case of a graphite cathode [33]. These particles, usually referred to as "macroparticles" emphasizing their massive nature compared to ions and electrons, have a wide range of size distribution. For carbon, large chunks of graphite (fractions of millimeters) are sometime ejected from the cathode - it is believed that shock-heated gas inclusions in the cathode contribute to these massive cathode losses. Due to their high temperature, carbon macroparticles are easily visible when leaving the cathode spot, and macroparticle velocities of $10-370 \mathrm{~m} / \mathrm{s}$ have been determined with a CCD camera [34]. Smaller macroparticles are much more frequent than $\mu$ m-size particles; the size distribution ranges well down to the nanoparticle range [35]. The presence of macro- and nanoparticles is detrimental to the quality of ultrathin films and, until recently, has prevented commercial application of cathodic arc plasma deposition in some fields such as the magnetic storage industry.

\section{B. Macroparticle filters}

Many attempts have been tried to reduce, and eventually eliminate macroparticles from the plasma and coating [36-40]. The term "macroparticles" is generically used for all particles, including nanoparticles. The most successful approach to macroparticle removal is based on the vast mass-tocharge difference of macroparticles and plasma particles. The plasma can be guided out of the lineof-sight from the cathode using curved magnetic fields, employing a combined magnetic and electric mechanism for electrons and ions, respectively. The motion of macroparticles is almost not influenced by the presence of fields, thus they move along straight trajectories, thereby being separated from the plasma.

In the literature, two basic constructions and filter philosophies have been described. They can be described as closed and open. The "classic" $90^{\circ}$ filter duct [41] employs a duct, a closed tube, surrounded a by set of magnetic field coils. The interior wall of the duct is equipped with baffles designed to catch or reflect macroparticles. While metal macroparticles tend to stick to baffles, graphite particles usually "bounce" back. Graphite particles may suffer multiple reflections and can fracture into several "sub-macroparticles." Consequently, there is a significant likelihood that carbon macroparticles, or fractions of them, arrive at the substrate via multiple reflections. Additionally, small nanoparticles may be transported through momentum exchanged with ions ("ion wind"). There are a numerous closed filters derived from the classic $90^{\circ}$ filter, including the $45^{\circ}$ filter [42], S-filter [43], segmented filter [44], filters of rectangular cross section [45, 46], and the out-of-plane doublebend (OPDB) filter $[47,48]$.

Open filters address the issue of particle reflection by removing the particle from the filter and plasma volume via openings [49-51]. Figure 1 shows an S-shaped open filter that consists of a bent 
solenoid. It is obvious that most macroparticles can leave the plasma volume, and some are removed even if they hit a turn of the magnetic field coil.

We have produced thin and ultrathin carbon films using different types of filters: a closed Sfilter [43], an open S-filter, a prototype twist filter (twisted S-filter) [52], and a second-generation twist filter. The closed and open S-filters in the present experiments had the following dimensions and parameters. Closed filter: two $90^{\circ}$ bents (in-plane), wall material stainless steel (bellows) of 0.4 $\mathrm{mm}$ thickness, inner diameter 2.50 inches $(6.35 \mathrm{~cm})$, curvature radius $10 \mathrm{~cm}$, magnetic field about 45 mT; open filter: two $90^{\circ}$ bents of open coil (in-plane), round copper wire of $2.25 \mathrm{~mm}$ diameter, inner diameter $5.5 \mathrm{~cm}$, curvature radius $6 \mathrm{~cm}$, magnetic field about $50 \mathrm{mT}$. The relatively novel twist filter is described in more detail below.

\section{Twist Filter System}

In recent work [52], a new open filter design was presented that is essentially a "twisted" Sshaped open solenoid, or "twist filter" for short. The prototype of the twist filter system is shown in Fig. 2; the two open $90^{\circ}$ sections of the filter are twisted by $90^{\circ}$. The design is based on several paradigms:

1) The filter must be short to minimize plasma losses [49].

2) The source (and thus the cathode) must be small to be compatible with the entrance size of the filter.

3) If the (consumable!) cathode is small, it needs to be replenished via a cathode feed mechanism.

4) If the source and filter are small, heating constraints can be alleviated by operating in pulsed mode.

5) Pulsed mode operation can be performed at relatively high arc currents, leading to reasonable average plasma production, possibly with enhanced plasma properties such as slightly enhanced average ion charge state and reduced macroparticle production compared to DC operation [53].

6) In the pulsed mode, the high arc current can be used to generate a strong magnetic filter field that is synchronized with plasma production.

7) Pulsed operation can use simple and very reliable arc initiation such as the "triggerless" mechanism [54].

8) The system needs a macroparticle "firewall", i.e. a wall separating the source and filter area from the clean substrate area.

9) The system needs a designated region in which macroparticles are collected for removal on a regular maintenance schedule. This area is located under the plasma source and filter.

10) The plasma exiting the filtered is highly focused but a uniform deposition over a relatively large area (e.g. wafer of $95 \mathrm{~mm}$ diameter) is required. Therefore, a plasma expansion zone and a plasma homogenizer are needed.

11) All parts of the system (source, filter, power supply, firewall, homogenizer, etc) need to be wellmatched.

The Twist Filter system is a consequent realization of the design paradigms. The prototype version shown in Figure 2 consists of two $90^{\circ}$ coil bents that are twisted by $90^{\circ}$. The filter's inner diameter is $30 \mathrm{~mm}$, and its outer diameter is $48 \mathrm{~mm}$. The coil "wire" had a flat cross section with a thickness of $1.0 \mathrm{~mm}$. The material was oxygen-free copper; this choice was made with the idea to have very good electrical conductivity, minimizing ohmic losses, and very good thermal conductivity, ensuring effective heat removal from water-cooled holding points. The filter-matching arc source did not have its own magnetic field but the filter's fringe field was found well-suited for source-filter coupling. The distance from the cathode surface to the filter entrance was $3 \mathrm{~cm}$. The source had a $1 / 4$ inch $(6.25 \mathrm{~mm})$ diameter graphite rod cathode that could be advanced as the cathode is eroded. The average cathode advancement was about $0.5 \mu \mathrm{m}$ per arc pulse, were a pulse is 
typically $1.5 \mathrm{kA}$ with $1 \mathrm{~ms}$ duration. The likelihood of macroparticle transport is greatly reduced while the plasma transport is impressive compared to other filter designs: the filtered ion current may reach up to $4 \%$ of the arc current. The coil turns have a flat cross-section promoting macroparticle reflection towards the outside of the filter volume, i.e., the coil acts as a baffle. The Twist Filter has a strong magnetic field $(0.25 \mathrm{mT} / \mathrm{A})$ providing excellent plasma confinement. At high currents $(>1$ $\mathrm{kA}$ ), not only electrons but also carbon ions are magnetized.

A second generation twist filter was installed at an R\&D deposition system in a class 100 cleanroom environment. The parameters were practically the same with the following exceptions: the twist of the two $90^{\circ}$ sections was only $45^{\circ}$ for reasons of space constrains (see Fig. 3), the anode was built as a pre-filter with baffle structure, the maximum total cathode advancement was increased to $15 \mathrm{~cm}$, the arc pulse length was increased to $1.0 \mathrm{~ms}$, and the substrates were mounted on a rotating substrate holder.

Arc initiation based on the "triggerless" principle [54] was used and found to be $100 \%$ reliable due to the high open-circuit voltage used $(900 \mathrm{~V})$. A total of about $10^{6}$ arc pulses have been made with the system so far without failure.

The chamber base pressure was about $10^{-5} \mathrm{~Pa}$. When the pulsed arc was operating with about 1 pulse per second, the pressure in the chamber initially increased to $10^{-3} \mathrm{~Pa}$ and settled at about $10^{-4} \mathrm{~Pa}$ after several 100 arc pulses. A residual gas analyzer showed that most of the background gas is water vapor, as it is typical for high-vacuum systems.

The plasma at the exit of the twist filter is highly focussed. Under its own pressure, the streaming plasma expands on its way to the substrate. Without special means, a deposited film will have a Gaussian thickness distribution with the thickest area in the center. A magnetic multipole, also known as a magnetic bucket, can be used to flatten the plasma density distribution leading to uniform films $[55,56]$. Magnetic multipoles can be made from strong permanent magnets or by using a wire structure as shown in Fig. 4. The electromagnetic homogenizer shown in Fig.4 was installed in the center between the twist filter exit and the substrate location. Using the homogenizer and a substrate rotation of $20 \mathrm{rpm}$., film uniformity of $\pm 2 \%$ could be achieved over an area of $95 \mathrm{~mm}$ diameter for films thicker than $10 \mathrm{~nm}$. Films of $3 \mathrm{~nm}$ showed appearently greater non-uniformity which is most likely due to the limitations of ellipsometry. One has to realize that $3 \%$ of a nominal thickness of 3 $\mathrm{nm}$ is $0.09 \mathrm{~nm}$, that is about half the average bond length between individual carbon atoms of amorphous carbon!

Film thickness and graphite cathode rod usage were very reproducible and could be predicted simply by counting arc pulses. The pulse number - thickness relationship was about linear although we found that the output per pulse increases slightly and reproducibly during a deposition run. We attribute this to increasing cathode temperature and erosion.

The carbon ion energy was measured specifically for the second generation twist filter. The method used is a time-of-flight measurement plus a correction due to the sheath in front of the substrate. The time delay between an intentional modulation of the arc current and Langmuir probe ion current gives the ion velocity in the plasma. The Langmuir probe was located at the substrate location $220 \mathrm{~mm}$ from the exit of the twist filter. The total path length between the cathode surface and the Langmuir probe was $425 \mathrm{~mm}$. The measured time difference between arc current maximum and ion current maximum was $18 \mu \mathrm{s}$, resulting in a velocity of $2.36 \times 10^{4} \mathrm{~m} / \mathrm{s}$ or an energy of 34.6 $\mathrm{eV}$. In order to estimate the plasma potential, a second measurement was done with the Langmuir probe floating. The floating potential is close to the plasma potential and easy to measure. The floating potential for a vacuum arc carbon plasma is about 4 volts negative with respect to the plasma potential [57]. With some fluctuations, the floating potential was found to be about $2 \mathrm{~V}$ positive with respect to ground. In this system both the anode and the substrate were grounded. Therefore, the 
additional energy singly charged carbon ions gain when they are accelerated from the plasma potential to the substrate potential is about $6 \mathrm{eV}$, and thus the average total kinetic energy is about 40 $\mathrm{eV}$ when ions hits the substrate surface.

\section{SYNTHESIS AND PROPERTIES OF A-C FILMS SYNTHESIZED BY FILTERED CATHODIC PLASMA DEPOSITION}

It is known that the properties of a-C films can be tuned by carefully choosing the ion energy during deposition. Properties such as $\mathrm{sp}^{3}$ content, hardness, Young's modulus, density, and stress have a maximum when ions have a kinetic energy of about $100 \mathrm{eV}[6,58-60]$. While in most experiments the energy could be manipulated by substrate biasing, the second generation twist filter system had a permanently grounded, rotating substrate holder. In the latter case, the above mentioned $40 \mathrm{eV}$ ion energy applies.

\section{A. Corrosion resistance}

In a first round of experiments, closed and open S-filters were used with an arc current of $300 \mathrm{~A}$, $5 \mathrm{~ms}$ pulse duration, and 1 pulse per second repetition rate. Bursts of pulsed substrate bias were used ( $-100 \mathrm{~V}, 2 \mu \mathrm{s}$ on $/ 6 \mu \mathrm{s}$ off). The first $10 \%$ of the deposition process wered done at a pulsed bias of -2 $\mathrm{kV}$ to obtain good adhesion, however, this step may not be needed for ultrathin films. The substrates for the first experiments were low-resistivity $\mathrm{Si}<100>$ wafers of $2.5 \mathrm{~cm}$ diameter that were previously coated with a magnetic layer of $100 \mathrm{~nm}$ permalloy $(80 \% \mathrm{Ni} / 20 \% \mathrm{Fe})$ using industrystandard magnetron sputtering. On these substrates, three sets of a-C films were fabricated using a closed S-duct filter, an open S-filter, and the second generation of twist filter. Industry-standard a$\mathrm{C}: \mathrm{H}$ films were used as reference to compare film quality; the a-C:H films were obtained by magnetron sputter deposition using a graphite target with argon plasma containing 30 at. $\% \mathrm{H}_{2}$. Film thickness was measured with an n\&k reflectance spectrometer and a Dektak IID profilometer.

To test corrosion resistance, the films were evaluated after immersing them for $24 \mathrm{~h}$ in a solution of $0.5 \mathrm{~mol} \mathrm{NaCl}, 0.5 \mathrm{~mol}\left(\mathrm{NH}_{4}\right) \mathrm{H}_{2} \mathrm{PO}_{4}, 1 \mathrm{~g}$ Liquinox, and 1 liter of deionized $\mathrm{H}_{2} \mathrm{O}$. The specimens were rinsed in an ultrasonic bath of deionized water and dried with nitrogen. Inspection was done under an optical microscope at 100x magnification. The defect size and density was measured using a CCD camera, frame grabber, and Media Cybernetics' Image-Pro Plus image analysis software.

Fig. 5 shows the corrosion pinhole count versus film thickness. No significant difference in corrosion performance was noted for films thicker than $4 \mathrm{~nm}$, indicating that the a-C films produced were continuous down to $4 \mathrm{~nm}$ thickness. The pinhole count rises an order of magnitude at thickness less than $4 \mathrm{~nm}$ for closed S-filter films and also significantly for films produced with the open Sfilter. However, films of $3 \mathrm{~nm}$ thickness produced by the twist filter system still met the requirements that are normally applied to the industry-standard $7 \mathrm{~nm}$ a-C:H film. This shows that the twist filter system has indeed an improvement in filter capability.

In another round of experiments, focusing on twist-filter deposited carbon films, actual sliders were used as substrates to be coated with ultrathin a-C films. The sliders used in the study at UC Berkeley and IBM San Jose were commercially available pico-sliders (1 $\mathrm{mm} \times 1.25 \mathrm{~mm})$ made of $70 \% \mathrm{Al}_{2} \mathrm{O}_{3}-30 \% \mathrm{TiC}$ material with a magnetoresistive (MR) element. In studies at Read-Rite Corporation, the sliders had dual synthetic heads, a form of the GMR (giant magnetoresistive) class of recording heads. The sliders were clamped to an aluminum substrate holder at ground potential.

For these experiments, $3 \mathrm{~nm}$ and $4 \mathrm{~nm}$ a-C coatings were deposited on sets of sliders with $\mathrm{read} / \mathrm{write}$ heads. For corrosion tests, a variation of the "Battelle test" was applied: $48 \mathrm{~h}$ exposure at $30^{\circ} \mathrm{C}, 65 \%$ relative humidity, in the presence of $10 \mathrm{ppb}$ hydrogen sulfide, $10 \mathrm{ppb}$ chlorine gas, and 
$100 \mathrm{ppb}$ nitrous oxide. As shown in Fig. 6, the sliders coated with the Twist Filter survived the corrosion test, as shown in images obtained using a Nomarsky optical microscope. Confirming the first-round dip-corrosion tests, the Battelle tests indicate that the $3 \mathrm{~nm}$ a-C films were continuous. The tests show that the twist filter system can indeed deliver films of $3 \mathrm{~nm}$ that provide corrosion protection.

\section{B. Hardness and elastic modulus}

Hardness and elastic modulus were measured using a force/displacement transducer coupled to an AFM. A corner of a cubic diamond tip with a nominal radius of $50 \mathrm{~nm}$ was used to indent the sample at loads of $1 \mu \mathrm{N}$ to $10 \mathrm{mN}$. The measurement took indenter deformation [61] into acount. The results are shown in Fig. 7. Hardness and elastic modulus decrease with decreasing film thickness, in agreement with independent measurements [6]. If the data may be linearly fitted showing the wellknown proportionality $H \sim E$ [62].

Nanoindentation of ultrathin films is difficult because the effect of the substrate increases with decreasing film thickness, and the indenter tip radius is much larger than the indentation depth. Other methods such as dispersion measurements of ultrasonic waves are being perfected for ultrathin films [63]. Young's modulus measurements performed this way often give greater values than nanoindentation.

Although the hardness of the film in the sub-10-nm regime appears to be relatively low, one must be careful in equating hardness with the film's wear resistance. Fracture toughness may be more relevant than hardness, especially in the case of sliding wear [1]. Scratch tests of ultrathin, ionbeam-deposited carbon nitride films indicate film failure by brittle fracture followed by abrasive wear [14]. Nanoindentation and nanoscratching is being used to evaluate fracture toughness of ultrathin films [11, 64-66].

\section{Drag tests in ultra-high vacuum tribochamber}

An UHV tribochamber [67] was used to detect the gaseous products generated at the headdisk interface during drag tests. A quadrupole mass spectrometer monitored 15 different species, and friction and temperature data were recorded by strain gauge transducers and a thermocouple, respectively. Background intensities were recorded before the drag tests. The drag speed was $0.2 \mathrm{~m} / \mathrm{s}$ and the load $15 \mathrm{mN}$.

Initial drag tests with $5 \mathrm{~nm}$ cathodic-arc carbon overcoats (closed S-filter) on disks revealed promising tribo-chemical properties against uncoated $\mathrm{Al}_{2} \mathrm{O}_{3}-\mathrm{TiC}$ sliders [2]. The cathodic-arc carbon overcoat reduced the catalytic decomposition of perfluoropolyether ZDOL 2000 lubricant commonly used in disk drive applications [68]. According to the catalytic decomposition mechanism [2], hydrogen generated from the overcoat is a key component of the reaction that occurs during sliding. Since cathodic-arc carbon films have relatively low hydrogen content, the catalytic decomposition should be hindered. This was confirmed in subsequent drag tests that involved $5 \mathrm{~nm}$ a-C:H and cathodic-arc a-C coated disks in contact with uncoated $\mathrm{Al}_{2} \mathrm{O}_{3}-\mathrm{TiC}$ sliders [69].

\section{Measurements of the magnetically dead layer}

To investigate the dead layer thickness, a layer of $20 \mathrm{~nm} \mathrm{NiFe}(18 \% \mathrm{Fe})$ was coated on $\mathrm{Si}$ substrate. The saturated magnetic flux density $\mathrm{B}_{\mathrm{s}}$ was measured before and after carbon deposition using a B-H looper. From the loss of $\mathrm{B}_{\mathrm{s}}$ one can calculate the approximate thickness of the dead layer. This technique was applied to a-C films synthesized with the twist filter system, and the magnetically dead layer was found to be about $0.5 \mathrm{~nm}$ which is close to the resolution limit of the method. 


\section{E. Hydrogen content}

The hydrogen content of twist-filtered a-C film was determined by Nuclear Resonance Analysis (NRA). A silicon specimen deposited with a twist filter a-C film of about $10 \mathrm{~nm}$ thickness yielded the surprisingly high $\mathrm{H}$-concentration of 9-11\%. From other experiments we have evidence that a pulsed vacuum arc process with a strong magnetic field in a high-vacuum environment does indeed produce significant amounts of hydrogen. Schneider and co-workers $[70,71]$ have shown that residual water vapor can be efficiently ionized when a magnetic field is present. The hydrogen content in alumina films deposited by filtered cathodic arcs was found to be about $8 \%$ [72]. Interestingly, cathodic arc ta-C films made several years ago at Berkeley Lab with a $90^{\circ}$ filter at much lower magnetic field strength showed only 1-3\% hydrogen content. These (unpublished) measurements were made with Elastic Recoil Spectroscopy (ERS). The difference in the results could be associated with not only possibly different vacuum base pressures but also by the degree of ionization of the water vapor due to the higher magnetic field of the twist filter.

\section{CONCLUSIONS AND OUTLOOK}

The development of improved macroparticle filters enables cathodic arc plasma deposition to produce thin and ultrathin films of good quality. Open filters address the reflection issue that has plagued traditional closed filter ducts. The most complete removal of carbon macroparticles was achieved by an open twisted S-filter dubbed "twist filter". It has been shown that ultrathin a-C films down to $3 \mathrm{~nm}$ could meet the requirements of the magnetic data storage industry. For storage densities approaching $100 \mathrm{Gbit} / \mathrm{in}^{2}$, current research focuses on the synthesis and analysis of even thinner films as well as on the improvement of uniformity and deposition rate.

\section{ACKNOWLEDGEMENTS}

The authors gratefully acknowledge the support by Robert A. MacGill, Tom Miller, Thomas A. McVeigh, Othon R. Monteiro, and Ian G. Brown of LBNL, Berkeley; Marcela M.M. Bilek, University of Cambridge, now at the University of Sydney, David Baldwin, Tony Lovelace, and Frank Cumbo of CVC, Inc.; Niranjan Gopinathan, Carolyn Robinson, and Bharti Patel of Read-Rite Inc., and David B. Bogy of UC Berkeley. This work was supported through the CRADA BG98084(01) of the ER-LTR Program of the U.S. Department of Energy, under Contract No. DE-AC0376SF00098, by CVC-Veeco, Inc., the CRADA Industrial Partner, by the National Storage Industry Consortium (NSIC), and the Computer Mechanics Laboratory at the University of California at Berkeley. 


\section{REFERENCES}

[1] H. Tsai and D. B. Bogy, "Critical Review: Characterization of diamondlike carbon films and their application as overcoats on thin-film media for magnetic recording," J. Vac. Sci. Technol. $A$, vol. 5, pp. 3287-3312, 1987.

[2] C. S. Bhatia, W. Fong, C. Y. Chen, J. Wei, D. Bogy, S. Anders, T. Stammler, and J. Stöhr, "Tribo-chemistry at the head/disk interface," IEEE Trans. Magnetics, vol. 35, pp. 910-915, 1999.

[3] P. R. Goglia, J. Berkowitz, J. Hoehn, A. Xidis, and L. Stover, "Diamond-like carbon applications in high density hard disc recording heads," Diamond Rel. Mat., vol. 10, pp. 271-277, 2001.

[4] D. R. McKenzie, D. Muller, and B. A. Pailthorpe, "Compressive-stress-induced formation of thin-film tetrahedral amorphous carbon," Phys. Rev. Lett., vol. 67, pp. 773-776, 1991.

[5] J. Robertson, "Deposition mechanism for promoting $\mathrm{sp}^{3}$ bonding in diamond-like carbon," Diamond \& Rel. Mat., vol. 2, pp. 984-989, 1993.

[6] G. M. Pharr, D. L. Callahan, D. McAdams, T. Y. Tsui, S. Anders, A. Anders, J. W. Ager, I. G. Brown, C. S. Bhatia, S. R. P. Silva, and J. Robertson, "Hardness, elastic modulus, and structure of very hard carbon films produced by cathodic-arc deposition with substrate bias," Appl. Phys. Lett., vol. 68, pp. 779-781, 1996.

[7] M. Chhowalla, J. Roberson, C. W. Chen, S. R. P. Silva, C. A. Davis, G. A. J. Amaratunga, and W. I. Milne, "Influence of ion energies and substrate temperature on the optical and electronic properties of tetrahedral amorphous carbon (ta-C) films," J. Appl. Phys., vol. 81, pp. 139-145, 1997.

[8] C. A. Davis, G. A. J. Amaratunga, and K. M. Knwoles, "Growth mechanism and cross-sectional structure of tetrahedral amorphous carbon thin films," IEEE Trans. of Plasma Sci., vol. 80, pp. 3280-3283, 1998.

[9] H. U. Jäger and K. Albe, "Molecular-dynamics simulation of steady-state growth of iondeposited tetrahedral amorphous carbon films," J. Appl. Phys., vol. 88, pp. 1129-1135, 2000.

[10] P. C. Kelires, "Intrinsic stress and local rigidity in tetrahedral amorphous carbon," Phys. Rev. B, vol. 62, pp. 15686-15694, 2000.

[11] P. Lemoine, R. W. Lamberton, A. A. Ogwu, J. F. Zhao, P. Maguire, and J. McLaughlin, "Complementary analysis techniques for the morphological study of ultrathin amorphous carbon films,” Journal of Applied Physics, vol. 86, pp. 6564-6570, 1999.

[12] B. Wei, B. Zhang, and K. E. Johnson, "Nitrogen-induced modifications in microstructure and wear durability of ultrathin amorphous-carbon films," J. Appl. Phys., vol. 83, pp. 2491-2499, 1998.

[13] A. Stanishevsky, "Quasiamorphous carbon and carbon nitride films deposited from the plasma of pulsed cathodic arc discharge," Chaos, Solitons \& Fractals, vol. 10, pp. 2045-2066, 1999.

[14] M. Bai, K. Kato, N. Umehara, Y. Miyake, J. Xu, and H. Tokisue, "Scratch-wear resistance of nanoscale super thin carbon nitride overcoat evaluated by AFM with a diamond tip," Surf. \& Coat. Technol., vol. 126, pp. 181-194, 2000.

[15] Y. H. Cheng, B. K. Tay, S. P. Lau, X. Shi, H. C. Chua, X. L. Qiao, J. G. Chen, Y. P. Wu, and C. S. Xie, "Deposition of carbon nitride films by filtered cathodic vacuum arc combined with radio frequency ion beam source," Diamond Rel. Mat., vol. 9, pp. 2010-1018, 2000.

[16] I. I. Aksenov, S. I. Vakula, V. G. Padalka, V. E. Strel'nitskii, and V. M. Khoroshikh, "Highefficieny source of pure carbon plasma," Sov. Phys. Techn. Phys., vol. 25, pp. 1164-1166, 1980.

[17] J. R. Shi, X. Shi, Z. Sun, E. Liu, B. K. Tay, and X. Z. Jin, "Structural and mechanical properties of amorphous silicon-carbon alloy films deposited by filtered cathodic vacuum arc technique," Int. J. Mod. Phys. B, vol. 14, pp. 315-320, 2000. 
[18] O. R. Monteiro, M.-P. Delplancke-Ogletree, and I. G. Brown, "Tungsten-containing amorphous carbon films deposited by pulsed vacuum arc," Thin Solid Films, vol. 342, pp. 100-107, 1999.

[19] M. P. Siegal, J. C. Barbour, P. N. Provencio, D. R. Tallant, and T. A. Friedmann, "Amorphoustetrahedral diamondlike carbon layered structures resulting from film growth energetics," Appl. Phys. Lett., vol. 73, pp. 759-761, 1998.

[20] R. Lossy, D. L. Pappas, R. A. Roy, J. J. Cuomo, and V. H. Sura, "Filtered arc deposition of amorphous diamond," Appl. Phys. Lett., vol. 61, pp. 171-173, 1992.

[21] R. Lossy, D. L. Pappas, R. A. Roy, J. P. Doyle, and J. Bruley, "Properties of amorphous diamond films prepared by a filtered cathodic arc," J. Appl. Phys., vol. 77, pp. 4750-4756, 1995.

[22] S. Logothetidis, P. Patsalas, M. Gioti, A. Galdikas, and L. Pranevicius, "Growth kinetics of sputtered amorphous carbon thin films: composition studies and phenomenological model," Thin Solid Films, vol. 376, pp. 56-66, 2000.

[23] M. H. Sohn and S. I. Kim, "Effects of interface mixing on adhesion of amophous carbon films synthesized by variable-energy direct ion beam deposition," J. Vac. Sci. Technol. A, vol. 18, pp. 1983-1986, 2000.

[24] M. C. M. van der Sanden, R. J. Severens, R. F. G. Meulenbroeks, M. J. de Graaf, Z. Qing, D. K. Otobarev, R. Engeln, J. W. A. M. Gielen, J. A. M. van der Mullen, and D. C. Schram, "The role of hydrogen during plasma beam deposition of amorphous thin films," Surf. \& Coat. Technol., vol. 74-75, pp. 1-9, 1995.

[25] H. A. Durand, K. Sekine, K. Etoh, K. Ito, and I. Kataoka, "Dynamic behavior of carbon ultrathin film formation," J. Appl. Phys., vol. 84, pp. 2591-2596, 1998.

[26] K. Yamamoto, T. Watanabe, K. Wazumi, F. Kokai, Y. Koga, and S. Fujiwara, "The sp ${ }^{3}$ bond fraction in carbon films prepared by mass-separated ion beam deposition," Diamond Rel. Mat., vol. 10, pp. 895-899, 2001.

[27] M. K. Fung, K. H. Lai, C. Y. Chan, I. Bello, C. S. Lee, S. T. Lee, D. S. Mao, and X. Wang, "Mechanical properties and corrosion studies of amophous carbon on magnetic disks prepared by ECR plasma technique," Thin Solid Films, vol. 368, pp. 198-202, 2000.

[28] S. Anders, I. G. Brown, C. S. Bhatia, and D. B. Bogy, "Wanted: hard, thin coatings for nearcontact recording," Data Storage, vol. 4, pp. 31-38, 1997.

[29] S. Anders, C. S. Bhatia, W. Fong, R. Y. Lo, and D. B. Bogy, "Application of cathodic arc deposited amorphous hard carbon films to the head/disk tribology," Mat. Res. Soc. Symp. Proc., vol. 517, pp. 371-382, 1998.

[30] I. G. Brown, "Vacuum arc ion sources," Rev. Sci. Instrum., vol. 65, pp. 3061-3081, 1994.

[31] G. Y. Yushkov, A. Anders, E. M. Oks, and I. G. Brown, "Ion velocities in vacuum arc plasmas," J. Appl. Phys., vol. 88, pp. 5618-5622, 2000.

[32] B. Jüttner, V. F. Puchkarev, E. Hantzsche, and I. Beilis, "Cathode Spots," in Handbook of Vacuum Arc Science and Technology, R. L. Boxman, D. M. Sanders, and P. J. Martin, Eds. Park Ridge, New Jersey: Noyes, 1995, pp. 73-281.

[33] M. Kandah and J.-L. Meunier, "Study of microdroplet generation from vacuum arcs on graphite cathodes," J. Vac. Sci. Technol. A, vol. 13, pp. 2444-2450, 1995.

[34] T. Schülke and A. Anders, "Velocity distribution of carbon macroparticles generated by pulsed vacuum arcs,” Plasma Sources Sci. Technol., vol. 8, pp. 567-571, 1999.

[35] O. Monteiro and A. Anders, "Vacuum-arc-generated macroparticles in the nanometer range," IEEE Trans. Plasma Sci., vol. 27, pp. 1030-1033, 1999.

[36] D. M. Sanders, D. B. Boercker, and S. Falabella, "Coatings technology based on the vacuum arc - a review," IEEE Trans. Plasma Sci., vol. 18, pp. 883-894, 1990. 
[37] R. L. Boxman, V. Zhitomirsky, B. Alterkop, E. Gidalevitch, I. Beilis, M. Keidar, and S. Goldsmith, "Recent progress in filtered vacuum arc deposition," Surf. \& Coat. Technol, vol. 8687, pp. 243-253, 1996.

[38] R. L. Boxman and S. Goldsmith, "Macroparticle contamination in cathodic arc coatings: Generation, transport and control," Surf. \& Coat. Technol., vol. 52, pp. 39-50, 1992.

[39] A. Anders, "Approaches to rid cathodic arc plasma of macro- and nanoparticles: a review," Surf. \& Coat. Technol., vol. 120-121, pp. 319-330, 1999.

[40] R. L. Boxman, "Recent development in vacuum arc deposition," IEEE Trans. of Plasma Sci., vol. 29, this issue., 2001.

[41] I. I. Aksenov, V. A. Belous, and V. G. Padalka, "Apparatus to rid the plasma of a vacuum arc of macroparticles," Instrum. Exp. Tech., vol. 21, pp. 1416-1418, 1978.

[42] D. A. Baldwin and S. Fallabella, "Deposition processes utilizing a new filtered cathodic arc source," Proc. of the 38th Annual Techn. Conf., Society of Vacuum Coaters, Chicago, 1995, pp. 309-316.

[43] S. Anders, A. Anders, M. R. Dickinson, R. A. MacGill, and I. G. Brown, "S-shaped magnetic macroparticle filter for cathodic arc deposition," IEEE Trans. Plasma Sci., vol. 25, pp. 670-674, 1997.

[44] T. Witke, T. Schuelke, B. Schultrich, P. Siemroth, and J. Vetter, "Comparison of filtered highcurrent pulsed arc deposition (phi-HCA) with conventional vacuum arc methods," Surf. \& Coat. Technol., vol. 126, pp. 81-88, 2000.

[45] R. P. Welty, "Rectangular vacuum-arc plasma source," Patent US 5,480,527, Vapor Technologies, Inc.1996.

[46] V. Gorokhovsky, “Apparatus for Application of Coatings in Vacuum, Rectangular Filter," Patent US 5435900, 1995.

[47] X. Shi, B. K. Tay, H. S. Tan, E. Liu, J. Shi, L. K. Cheah, and X.Jin, "Transport of vacuum arc plasma through an off-plane double bend filtering duct," Thin Solid Films, vol. 345, pp. 1-6, 1999.

[48] X. Shi, B. G. Tay, and S. P. Lau, "The double bend filtered cathodic arc technology and its applications," Int. J. Mod. Phys. B, vol. 14, pp. 136-153, 2000.

[49] J. Storer, J. E. Galvin, and I. G. Brown, "Transport of vacuum arc plasma through straight and curved magnetic ducts," J. Appl. Phys., vol. 66, pp. 5245-5250, 1989.

[50] J. Koskinen, A. Anttila, and J.-P. Hirvonen, "Diamond-like carbon coatings by arc-discharge methods," Surf. Coat. Technol., vol. 47, pp. 180-187, 1991.

[51] A. Anttila, J. Salo, and R. Lappalainen, "High adhesion of diamond-like films achieved by the pulsed-arc discharge method," Mat. Letters, vol. 24, pp. 153-156, 1995.

[52] A. Anders and R. A. MacGill, "Twist Filter for the removal of macroparticles from cathodic arc plasmas," Surf. \& Coat. Technol., vol. 133-134, pp. 96-100, 2000.

[53] T. Schuelke, T. Witke, H.-J. Scheibe, P. Siemroth, B. Schultrich, O. Zimmer, and J. Vetter, "Comparison of DC and AC arc thin film deposition techniques," Surf. \& Coat. Technol., vol. 120-121, pp. 226-232, 1999.

[54] A. Anders, I. G. Brown, R. A. MacGill, and M. R. Dickinson, ""Triggerless" triggering of vacuum arcs,” J. Phys. D: Appl. Phys., vol. 31, pp. 584-587, 1998.

[55] M. M. M. Bilek, O. R. Monteiro, and I. G. Brown, "Optimization of film thickness profiles using a magnetic cusp homogenizer," Plasma Sources Sci. Technol., vol. 8, pp. 88-93, 1999.

[56] M. M. M. Bilek, A. Anders, and I. G. Brown, "Magnetic system for producing uniform coatings using a filtered cathodic arc," Plasma Sources Sci. Technol., pp. submitted, 2001. 
[57] A. Anders, "Growth and decay of macroparticles: A feasible approach to clean vacuum arc plasmas?," J. Appl. Phys., vol. 82, pp. 3679-3688, 1997.

[58] J. J. Cuomo, D. L. Pappas, J. Bruley, J. P. Doyle, and K. K. Saenger, "Vapor deposition process for amorphous carbon films with $\mathrm{sp}^{3}$ fractions approaching diamond," J. Appl. Phys., vol. 70, pp. 1706-1711, 1991.

[59] P. J. Fallon, V. S. Veerasamy, C. A. Davis, J. Robertson, G. A. J. Amaratunga, W. I. Milne, and J. Koskinen, "Properties of filtered-ion-beam-deposited diamondlike carbon as a function of ion energy," Phys. Rev. B, vol. 48, pp. 4777-4782, 1993.

[60] Y. Lifshitz, G. D. Lempert, S. Rotter, I. Avigal, C. Uzan-Saguy, R. Kalish, D. Marton, and J. W. Rabalais, "The effect of ion energy on the diamond-like graphitic $\mathrm{sp}^{3} / \mathrm{sp}^{2}$ nature of carbon films deposited by ion beams," Diamond \& Rel. Mater., vol. 3, pp. 542-546, 1994.

[61] G. M. Pharr, "Measurement of mechanical properties by ultra-low load indentation," Mat. Sci. \& Eng. A, vol. 253, pp. 151-159, 1998.

[62] D. Schneider, H.-J. Scheibe, T. Schwarz, and P. Hess, "Characterization of thin diamond-like carbon films by ultrasonic surface waves," Diamond \& Relat. Mater., vol. 2, pp. 1396-1401, 1993.

[63] D. Schneider, T. Witke, T. Schwarz, B. Schöneich, and B. Schultrich, "Testing ultra-thin films by laser-acoustics," Surf. \& Coat. Technol., vol. 126, pp. 136-141, 2000.

[64] X. Li and B. Bhushan, "Measurement of fracture toughness of ultr-thin amorphous carbon films," Thin Solid Films, vol. 315, pp. 214-221, 1998.

[65] X. Li and B. Bhushan, "Evaluation of fracture toughness of ultra-thin amorphous carbon coatings deposited by different deposition techniques," Thin Solid Films, vol. 355-356, pp. 330336, 1999.

[66] X. D. Li and B. Bhushan, "Micro/nanomechanical and tribological characterization of ultrathin amorphous carbon coatings," J. Mat. Res., vol. 14, pp. 2328-2337, 1999.

[67] X. H. Yun, D. B. Bogy, and C. S. Bhatia, "Wear of hydrogenated carbon coated disks by carbon coated and uncoated $\mathrm{Al}_{2} \mathrm{O}_{3} /$ TiC sliders in ultra high vacuum," IEEE Trans. Magnetics, vol. 32, pp. 3669-3671, 1996.

[68] C.-Y. Chen, D. B. Bogy, and C. S. Bhatia, "Tribochemistry of monodispersed ZDOL with hydrogenated carbon overcoats," J. Vac. Sci. Technol. A, vol. 18, pp. 1809-1817, 2000.

[69] W. Fong, "Fabrication and evaluation of $5 \mathrm{~nm}$ cathodic-arc carbon films for disk drive applications," in Department of Mechanical Engineering, Computer Mechanics Laboratory. Berkeley, CA: University of California at Berkeley, 1999.

[70] J. M. Schneider, A. Anders, B. Hjörvarsson, and L. Hultman, "Magnetic-field-dependent plasma composition of a pulsed arc in a high-vacuum ambient," Appl. Phys. Lett., vol. 76, pp. 1531$1533,2000$.

[71] J. M. Schneider, A. Anders, and G. Y. Yushkov, "Magnetic-field-dependent plasma composiiton of a pulsed aluminum arc in an oxygen ambient," Appl. Phys. Lett., vol. 78, pp. 150-152, 2001.

[72] J. M. Schneider, A. Anders, B. Hjörvarsson, I. Petrov, K. Macak, U. Helmerson, and J.-E. Sundgren, "Hydrogen uptake in alumina thin films synthesized from an aluminum plasma stream in an oxygen ambient," Appl. Phys. Lett., vol. 74, pp. 200-202, 1999. 


\section{Figure Captions}

Figure 1. S-shaped open filter guiding carbon plasma from a cathodic arc plasma source (right) to the substrate region (left). Carbon macroparticles are hot and can therefore easily be identified by their bright traces. Open-shutter photograph, arc current $1000 \mathrm{~A}$, pulse length $1 \mathrm{~ms}$.

Figure 2. Photograph of the prototype twist filter system (two $90^{\circ}$ sections, twisted by $90^{\circ}$, ID $30 \mathrm{~mm}$, OD $48 \mathrm{~mm}$ ) with its holding structure; the cathodic arc source with advancing cathode, and the arc power supply. For scale: the arc supply can be mounted in a standard 19" $(48.3 \mathrm{~cm})$ rack.

Figure 3. Mounting of the second generation twist filter (two $90^{\circ}$ sections twisted by $45^{\circ}$ ).

Figure 4. A simple electromagnetic multipole or "bucket" used to flatten the plasma density distribution in the alpha-version of the Twist Filter System. As with the Twist Filter, the arc current itself was used to generate the magnetic field. The pen is for size comparison.

Figure 5. Corrosion pinhole count in an area of $0.8 \times 1 \mathrm{~mm}^{2}$ versus thickness of a-C films synthesized with three filter systems. The horizontal line indicates the average pinhole count for a 7-nm RFsputtered a-C:H reference film that is considered acceptable.

Figure 6. Battelle corrosion test of 3-nm a-C coated read/write heads. Optical micrographs before (left column) and after (right column) the test. For comparison, the top four rows show heads that were coated using a DC carbon vacuum arc with a closed filter; the bottom four rows show heads coated with the twist filter system.

Figure 7. Hardness and elastic modulus of a-C films as a function of film thickness as determined by nanoindentation. 


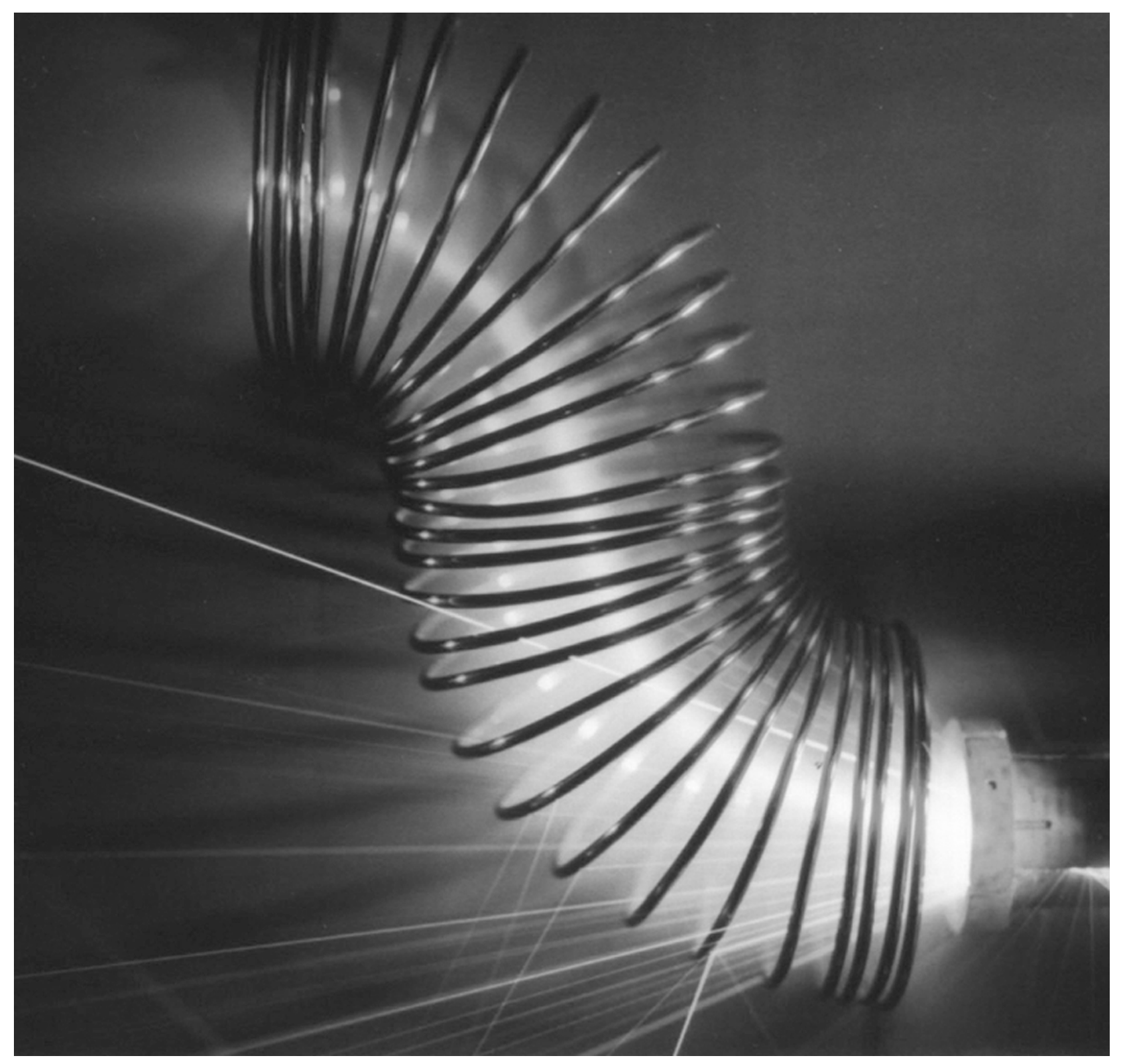

Figure 1 


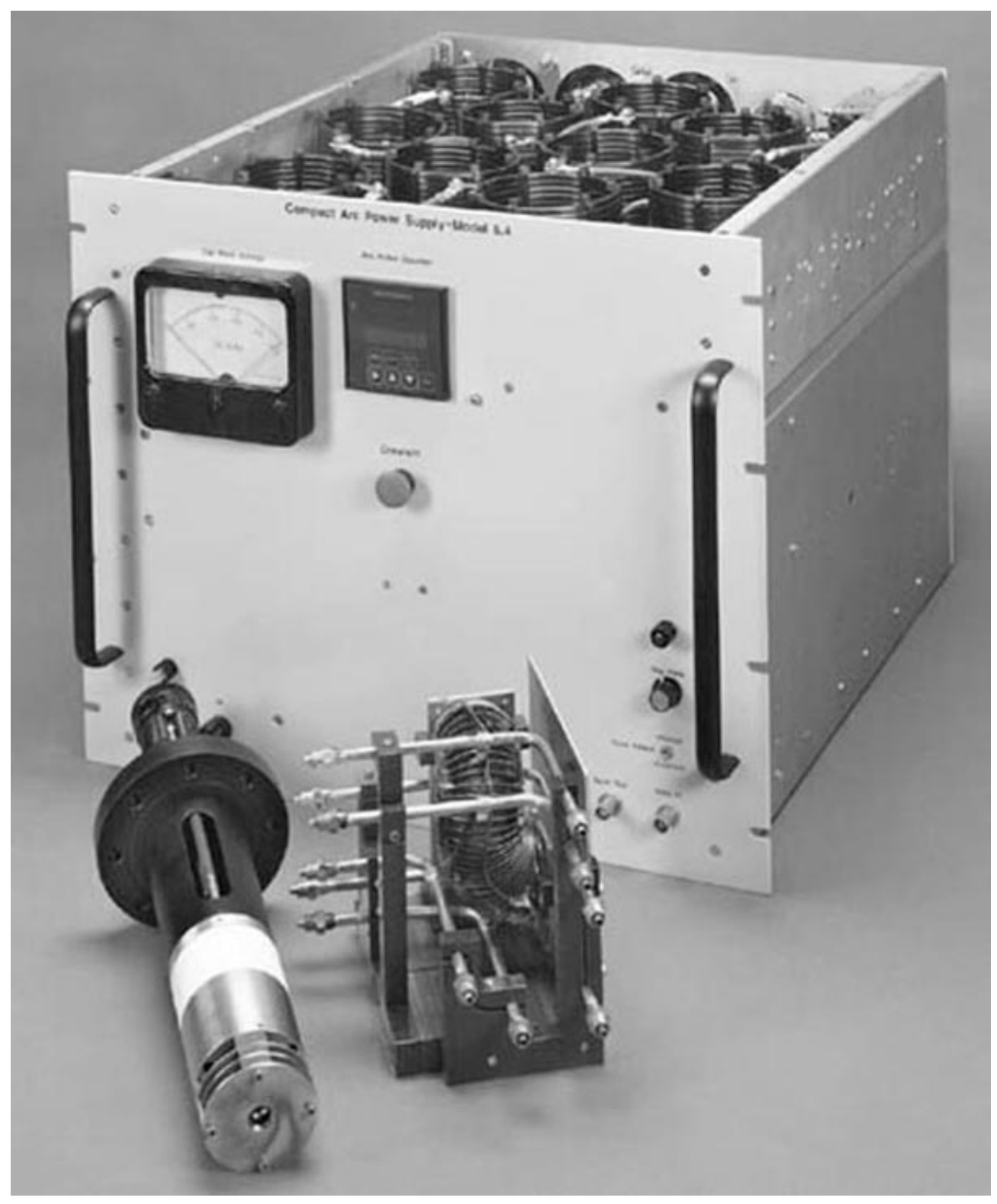

Figure 2 


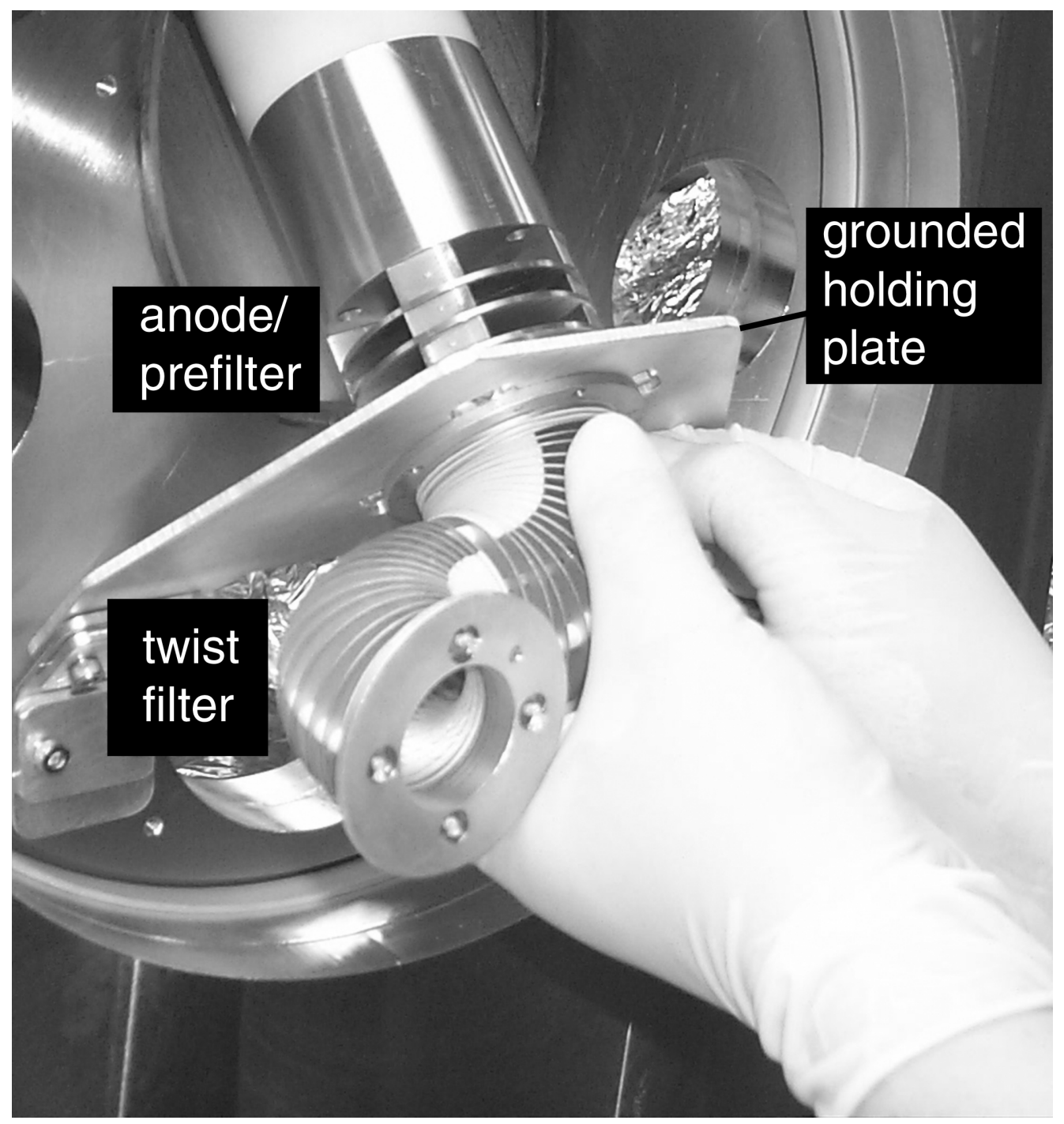

Figure 3 


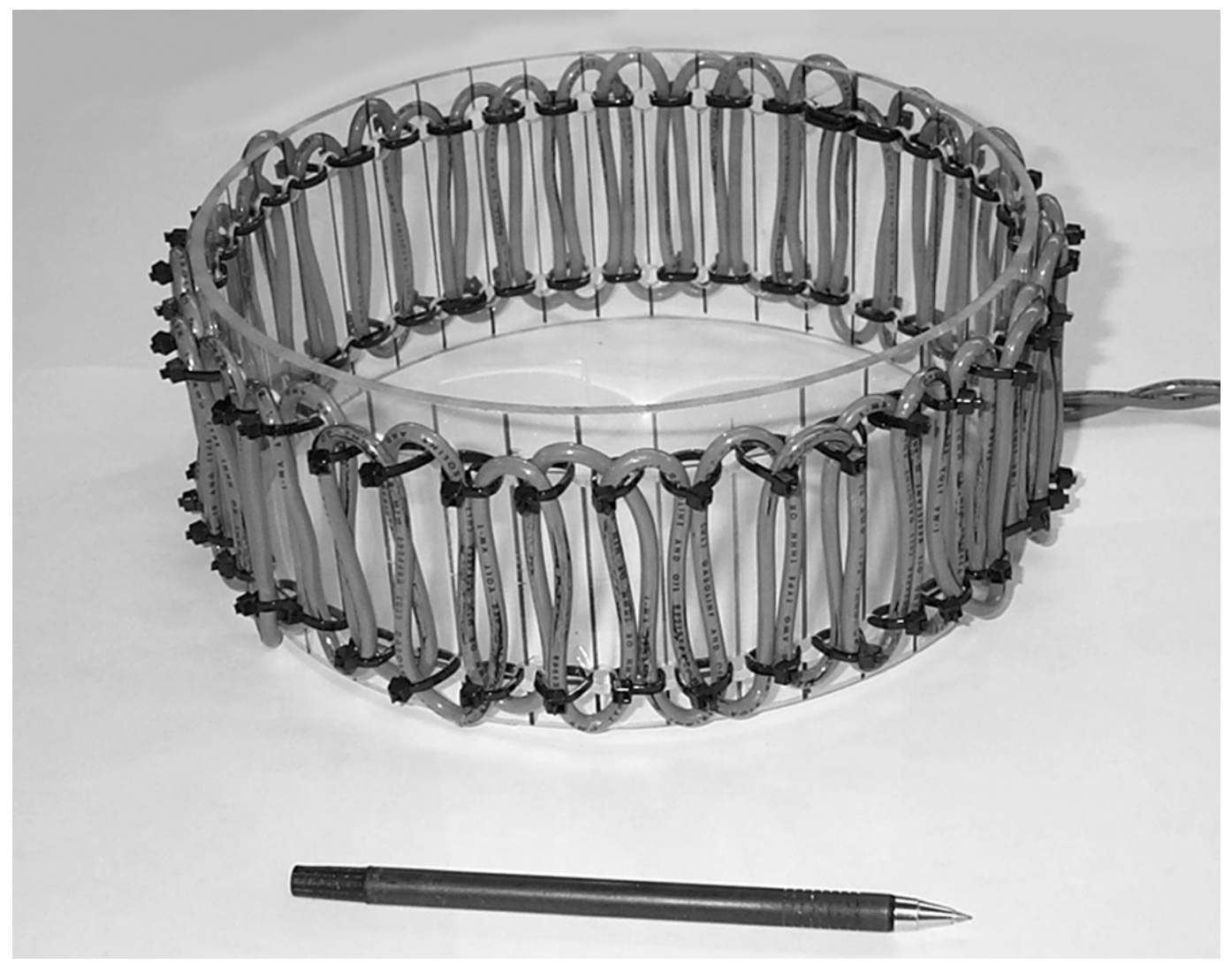

Figure 4 


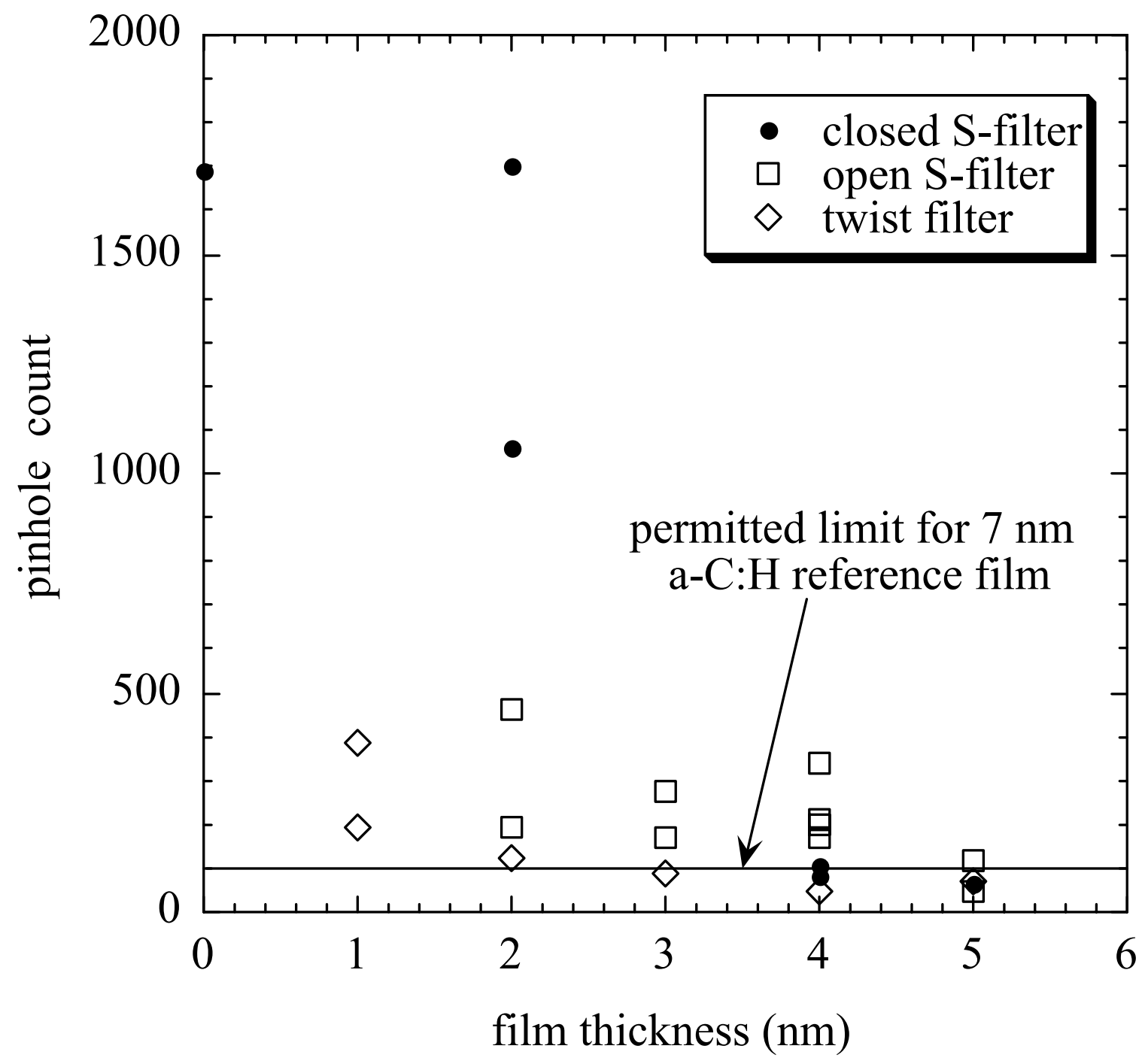

Figure 5 

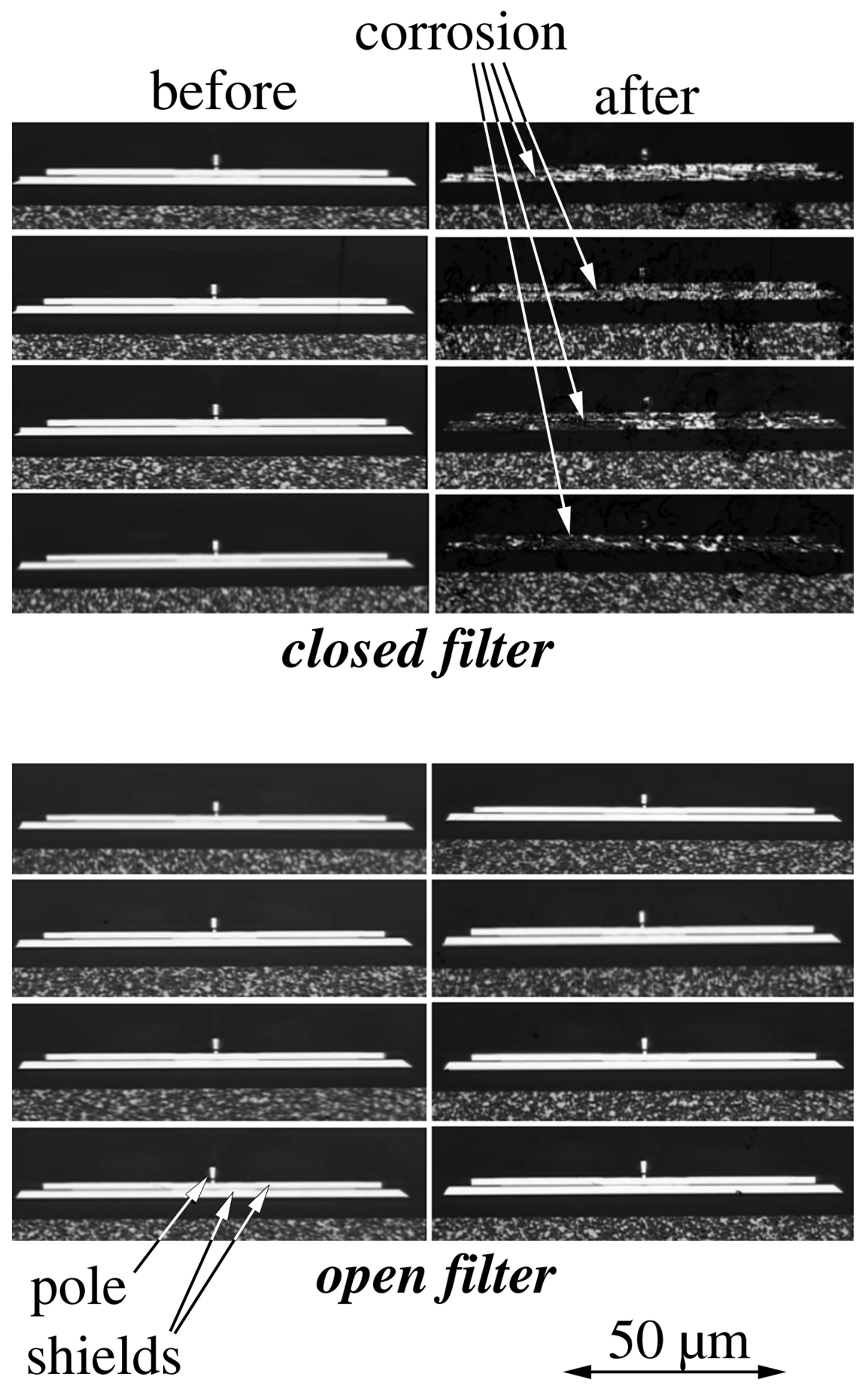

Figure 6 


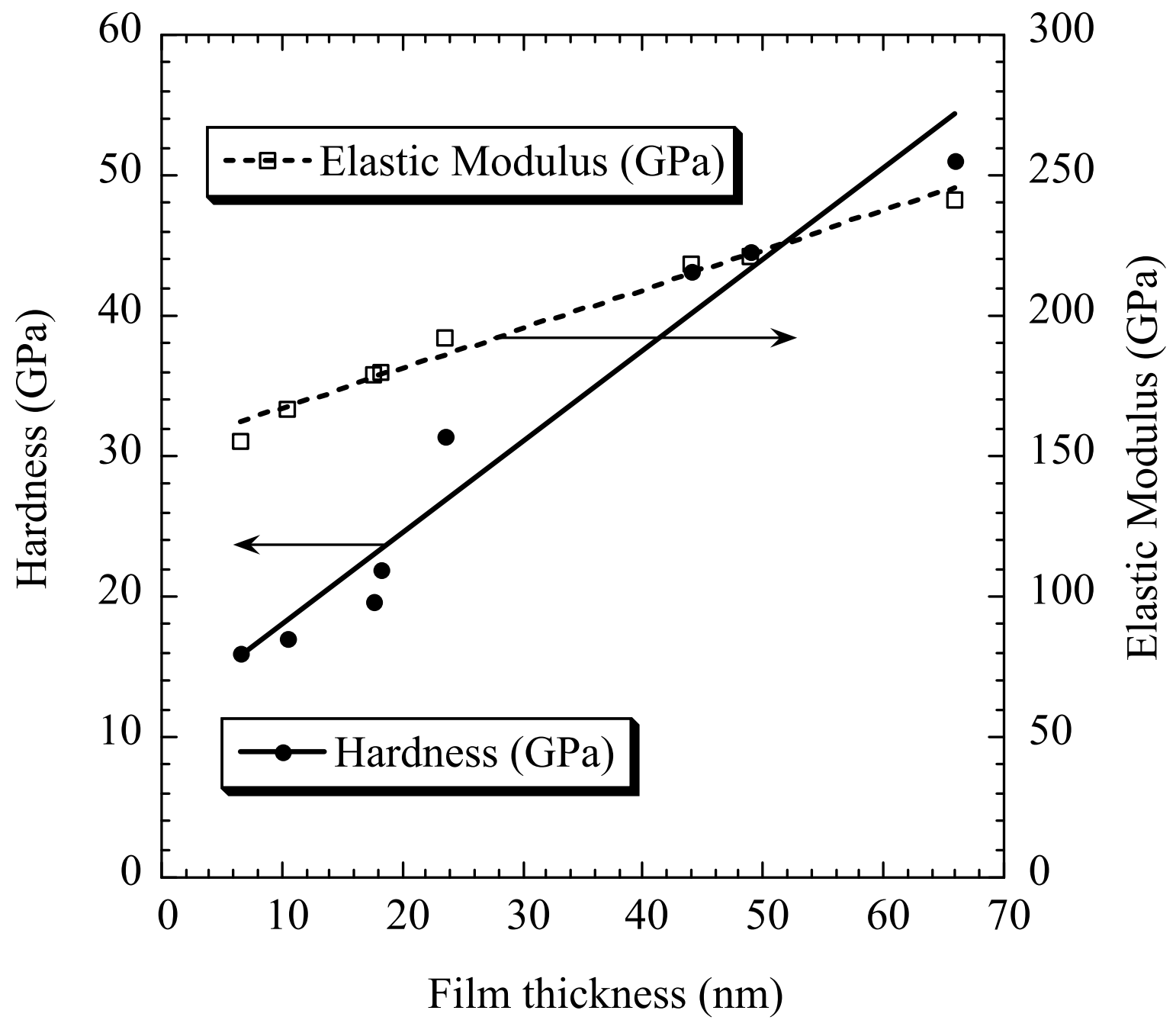

Figure 7 